\title{
Information and Communication Technology in Nigeria: Revolution or Evolution
}

\author{
L. A. Ogunsola and W. A. Aboyade \\ Hezekiah Oluwasanmi Library, Obafemi Awolowo University, Ile-Ife, Nigeria
}

KEYWORDS Information technology; library; information; revolution; communication; technology

\begin{abstract}
This paper presents an historical development of telecommunications starting from Lanlate I Satellite Earth Station which was Nigeria's first international satellite telecommunications gateway to the outside world. An overview of the general level of development of information technology in Nigeria is also highlighted and it also examines the extent to which it is being used in support of information delivery and communication in science and technology. The importance of information technology devices to the general development of national economy and educational advancement is also discussed. The paper emphasizes that for the survival and relevance of higher education institutions in Nigeria, ICT should be declared an institutional priority with adequate funding and support. It is finally concluded that the tremendous advancement in computer technology, software engineering and telecommunications as well as the resultant radical changes and advances in the techniques of data and information processing, storage, retrieval and dissemination in Nigeria within a decade is, no doubt, a revolution.
\end{abstract}

\section{INTRODUCTION}

Information has always played a very important part in human life. However, in the mid- $20^{\text {th }}$ century, the role of information increased immeasurably as a result of social progress and the vigorous development in science and technology. In addition, as Trostnikov (1970) has pointed out, rapid expansion of a mass of diversified information is occurring, which has received the name "information explosion". As a result, the need has arisen for a scientific approach to information and for elucidation of its most characteristic properties which has led to two principal changes in interpretation of the concept of information. First, it was broadened to include information exchange not only between man and man but also between machine and machine, as well as the exchange of signals in the animal and plant worlds. The pace of change brought by new technologies has had a significant effect on the way people live, work, and play worldwide. New and emerging technologies challenge the traditional process of teaching and learning, and the way education is managed. Information technology, while an important area of study in its own right, is having a major impact across all curriculum areas. Easy worldwide communication provides access to a vast array of data, challenging assimilation and assessment skills.

Rapid communication, plus increased access to IT in the home, at work, and in educational establishments, could mean that learning becomes a truly lifelong activity- an activity in which the pace of technological change forces constant evaluation of the learning process itself. Communication can be described as the process of transmitting and receiving ideas, information, and messages. In keeping with their complex nature and multiple applications, Information and Communication Technologies (ICTs) may be viewed in different ways. The World Bank defines ICTs as "the set of activities which facilitate by electronic means the processing, transmission and display of information" (Rodriguez and Wilson, 2000). ICTs "refers to technologies people use to share, distribute, gather information and to communicate through computers and computer networks" (ESCAP, 2000). ICTs can be described as a complex varied set of goods, applications and services used for producing, distributing, processing, transforming information(including) telecoms, TV and radio broadcasting, hardware and software, computer services and electronic media" (Marcelle, 2000). ICTs represent a cluster of associated technologies defined by their functional usage in information access and communication, of which one embodiment is the Internet. Hargittai (1999) defines the Internet technically and functionally as follows: "the Internet is a worldwide network of computers, but sociologically it is also important to consider it as a network of people using computers that make vast amounts of information available. Given the two (basic) services of the systemcommunication and information retrieval- the multitude of services allowed.....is unprecedented." ICTs, represented by the Internet, 
deliver "at once a worldwide broadcasting capacity, a mechanism for information dissemination, a medium for interaction between individuals and a marketplace for goods and services (Kiiski and Pohjole, 2000). As pointed out by Capron (2000), mails, telephone, TV and radio, books newspapers and periodicals are the traditional ways users send and receive information. However, data communications system-computer system that transmits data over communications lines such as telephone lines or cables have been evolving since the mid-1960s.

One of the most dramatic advances in communication potential- data communications- is found in the field of computer technology. Since the first development of the modern electronic digital computers in the $1940 \mathrm{~s}$, computerization has infiltrated almost every area of society in nations with advanced technology. Computers are available in many formats for use in industries, businesses, hospitals, schools, universities, transport networks and individual homes. Small or large, a computer network exists to provide computer users with the means of communicating and transferring information electronically. The use of Internet has revolutionized access to information for the business world, libraries, education and individuals. A few of the most popular include E-mail (electronic mail), World Wide Web, FTP (File Transfer Protocol), Usenet, and Telnet. The Internet and its technology continues to have a profound effect in promoting the sharing of information especially in academic world, making possible rapid transactions among businesses, and supporting global collaboration among individuals and organizations. Learning resource centres now often contain learning materials published on CD-ROM and most colleges are connected to the Internet. These technologies have the potential to develop "virtual campuses" and thus increase student access and participation. Information technology provides access to mainstream materials and enables students to express their thoughts in words, designs and activities despite their disabilities. World Wide Web can be described as a library of resources available to computer users through the global Internet. It enables users to view a wide variety of information, including magazine, archives, public and college library resources, and current world and business news. WWW resources are organized so that users can easily move from one resource to another.
Using IT, learners can absorb more information and take less time to do so.

It is the objective of this paper to highlight the growth and the importance of ICTs in Nigeria. Attempt is made to trace the development of IT especially telecommunications system in Nigeria and the growing popularity of IT devices in both the educational and economic development of Nigeria as a whole. The paper presents an overview of the general level of development of information technology in Nigeria, and then examines the extent to which it is being used in support of information delivery and communication in science and technology.

\section{INFORMATION SCIENCE AND LIBRARIANSHIP}

There seems to be no one definition generally accepted for the field of information science as a discipline distinct from librarianship. The Georgia Institute of Technology Conference (1961) defines information science as: "the science that investigates the properties and behaviour of information, the forces governing the flow of information, and the means of processing formation for optimum accessibility and usability". Recent definition according to Microsoft Encarta Encyclopedia (2002) defines Information Science as an academic discipline that deals with the generation, collection, organization, storage, retrieval, and dissemination of recorded knowledge. It is sometimes mistakenly used as a synonym for library science, but though related, it is a separate discipline. Librarians are primarily concerned with such tasks as evaluating, processing, and retrieving information, and with collection development and bibliographic processes and products. Increasingly, though, librarians are being called upon to learn audio-visual and computer technologies and applications, such as CD-ROM and the Internet. The librarian is more concerned with the management of systems, the information scientist with their creation. Information Scientists analyze the many and various phenomena that affect any aspect of information. They are interested in determining such things as the life circle and utility of literature on a given subject (bibliometrics), patterns of authorship (co-citation analysis), and the impact of reading on groups and societies (social epistemology). The distinct difference which now exists between information science and libra- 
rianship is that the former is concerned with information or data while the later relates specifically to document handling.

For the information scientist, therefore, the library is only one of several alternative sites for information storage and service, systems may be based in, for example, information banks, archives, or organizations such as schools and businesses, medical centres, computing companies, university research centres, and abstracting and indexing companies. By 1980, information science had become a thoroughly interdisciplinary field, and in recent times areas such as artificial intelligence and information technology in education have become especially important. It must be realized that Information Science is indispensable to the progress of librarianship and it comprises that set of research necessary to support the profession now being called librarianship. The relationship between information science and librarianship is like that between medical science and the practice of medicine. As pointed out by Osundina (1973), "information science, practically speaking, is not antithetical to librarianship, rather it is an ally and it is very important for librarians to accept this". For now both may speak with varying tongues, eventually the objectives are the same. The name information science developed because of growing dissatisfaction with the conservative attitude of librarianship to 'information'. The library of today should no longer be a library of the $17^{\text {th }}$ century image. Today's library, university and special libraries must be information systems. The library of today should not merely store documents and preserve them; it must also devise means by which the contents of such documents can be rapidly and effectively transmitted for use.

The product of present day educational processes for library practice is a set of welltrained clerical officers, trained in the daily routine of library work, but who are unable to innovate or create for new situations. What more do we expect when these students are taught only routine courses such as cataloguing, acquisitions, classification, library administration and reference service. Although the creative minds among them are usually able to adjust to meet new situations, they are compelled by their orientation to do so along existing paths. This kind of education may meet the needs of some libraries, but it completely fails to meet the needs of today and future information climate. Our library schools must include courses in information theory, information storage device, indexing, abstracting, information analysis, application of computer in information handling, psychology, information dissemination, information system design, etc. This does not mean that people who are called librarians can no longer operate libraries without an education based on or including these ideals. What seems clear is that they now deal with increasingly complex developments and if they are to cope with the new environment, they must understand sophisticated approaches.

Nigerian libraries are now gradually being computerized especially in the universities. But there is urgent need to introduce computer literacy even right from primary to university education. Computers are sometimes thoughtunjustifiable - to demand deep technical knowledge or proficiency in mathematics and electronics. In actuality, computers, like any other discipline, inspire different levels of expertise. On the least specialized level, computer literacy involves knowing how to turn on a computer, start and stop simple application programmes, and save and print information. All these must be known to library staffs and users especially in our universities. As far as library educational development is concerned in Nigeria and other developing countries, computers are essential tools in almost every field of research and applied technology. More recently, the introduction of microcomputers, microprocessors and computer combinations have made possible the development of library facilities especially in Nigerian universities and research institutions. The managers of Nigerian educational system especially the professional librarians should view ICT as a complementary tool in the development and dissemination of information and should not be a replacement of the traditional library. Even today, in its infant state, as revealed by Ebeniro (2000) the Internet is the largest library, bookstore, auction house, and art gallery in the world. No human can possibly digest it at all.

The library as the life blood of higher education institutions can benefit tremendously from the facilities provided by the ICT, The library can be transformed in to a new information services unit, providing electronic cataloguing, electronic on-line, public access catalogue, electronic acquisition and serials control, electronic inter-library loan and electronic circulation functions. How- 
ever, many of the libraries in the higher education institutions in Nigeria and other African countries are yet to take advantages of the facilities of modern ICT. In view of the lack of funds for the libraries, it has not been possible to stock modern books and journals, which are now expensive in view of the economic recession and currency devaluation in many African countries. Digitalization is taking in many of the libraries and library information networks established with connectivity through the university campus network to the Internet. The libraries could also use modern ICT facilities to provide contents and information dissemination, by the electronic publishing research theses and dissertations. There is no doubt that students will benefit from the millions of pages of relevant information on the Web if the university and library management can provide adequate ICT facilities.

\section{INFORMATIONANDCOMMUNICATION TECHNOLOGYINNIGERIA}

Computing and Telecommunications (and also such areas as broadcasting and publishing) used to be quite distinct industries, involving distinct technologies. Now they have covered around certain key activities such as use of the Internet. The pace of adoption of new IT has been very speedy: it is markedly more rapid than that of earlier revolutionary technologies such as the steam engine or electric motor. But in Nigeria, information technology is rather a recent phenomenon. Telecommunications, the oldest element, had a modest beginning with the first trunk telephone service between two towns in 1923 (Ofulue, 1980). It was not until the 1950s that substantial expansion began with the introduction of VHF radio systems, 116 manual and five automatic telephone exchanges. In other to enhance the quality of telecommunications services in Nigeria, the telecommunications arm of the Post and Telegraph Department and the Nigerian External Telecommunications Limited, which previously managed the domestic and external services respectively, were merged in 1984 to single profit-oriented limited liability company called NITEL. Under NITEL, the number of automatic switching centres in Nigeria grew to 227 in July 1986. The national telex network grew also to a total capacity of 12,800 lines with only one international exchange having 1,500 trunks. By this time, the transmission media for toll and trunks included terrestrial microwave, coaxial cable, and domestic satellite (Unchidiuno, 1986). But it must be realized that more attention was paid to communication with the outside world than the development and enhancement of the internal telecommunications system. The Lanlate Satellite Earth Station, Nigeria's first international satellite telecommunication gateway, became operational in March 1971 with one antenna (Lanlate I) tracking the Indian Ocean INTELSTAT satellite. A second antenna called Lanlate II was added in December 1975. This one operates with the Atlantic Ocean satellite. By the end of 1986, the two antennas provided a total 417 circuits, namely 248 in the Atlantic Ocean Region and 169 in the Indian Ocean Region. Another international earth station has been built at Kujama in Kaduna State. With these facilities, most of Nigeria's external telecommunications, including telephone, telex, facsimile, and television, have been by satellite.

The Nigeria Domestic Satellite System was established in 1975 with a network of six 11-metre earth stations operating on a leased INTELSAT satellite transponder. The network was subsequently expanded to comprise three leased transponders each of $36 \mathrm{MHz}, 20$ earth stations, a network monitor and control station, and backhaul radio links between the DOMSAT earth stations and NITEL as well as stations of Nigerian Television Authority (Unchidiuno,1986). The first transponder was allocated for television transmission, while the other two were reserved for telecommunication services. But it must be realized that the history of the development of telecommunications in Nigeria is characterized by unfulfilled objectives. Achievements have been consistently short of demand for services. It must be noted that the present analogue system on which the national telecommunications network is based is outdated and this has been a serious limitation to the efficiency of the telecommunications network in this country. But there are, however some indications that telecommunications in Nigeria may improve in future. NITEL is still following up its plans for a digital network though progress has been very slow. Recently, it was reported that the nation's digitalized earth station, expected to facilitate telecommunications link between Nigeria and other parts of the world, was ready for use (Ikhurionan et al., 1991). This will be the third gateway after Lanlate in Oyo State and Kujama in Kaduna State. The first 
phase of the digital project at Abuja was commissioned in 1990, while work is in progress on several other projects.

Some organizations have ventured out developing their own networks. The greatest achievements are those of the Nigerian National Petroleum Corporation (NNPC), which in 1990, installed a digital communications network regarded as the largest in Africa. It is a hybrid network of fibre optics and coaxial cable. The turnkey system interconnects all the vital sites and offices of the NNPC, and provides facilities for automatic voice dialing, teleconferencing, and transmission of data, facsimile and telex. Nevertheless, a truly national network is most desirable solution, but this is not yet in sight. Nigeria also had a late start in the use of computers, but a start haven been made, the growth in use has been quite remarkable. A tremendous impetus was given to the computer market by the growing interest in microcomputers in the past decade. The computer installations are widely distributed in universities, government departments and agencies, banks, commercial establishments, and industries. It must be realized that the private sector has, however, risen to a position of dominance in the use of computers. Perhaps in any discussion of application of modern technology in the library, the first thing that comes to mind is the computer. One advancement that has been achieved in the area of application of technology is that, unlike previously, the librarian does not have to be literate in the various technologies before employing them. In other words, he does not have to be a technical expert before using any form of technology, or a programmer before using a computer. However, he still requires some technological knowledge, albeit at an abstract and intellectual level. Furthermore, and this is important for us in developing countries, the capacities of each technology should be well written up by the vendor and understood by the librarian before committing himself. Whatever one chooses to call it, the computer has made such a tremendous impact on the organization, management and dissemination of information that it readily commends itself to any library ready to accept it. As pointed out by Ukoh (1984) "computer has become such a household word in the developed world that libraries should see it as a great opportunity which should be taken up as soon as possible, but sooner than later". An earlier survey by Uborgu and Gupta (1987) revealed that while computer market in Nigeria has been growing rapidly, library has not contributed much to the growth. It is probably not right to say that libraries have not been aware of benefit of automation. Their survey showed that many libraries in Nigeria believed in the necessity for automation. The advantages of computerized system greatly outweigh the disadvantages so that, with proper planning, libraries will derive enormous benefits from the venture. There is no area of library operation to which the computer has not been applied with tremendous gains. As asserted by Nilles (1987), "the new technology is just based on information-electronic, telecommunications, their component parts, and the software that animates them". With these benefits of computerized library system, one can ask how much of these are in use in Nigeria? In this regard, one can say that Nigerian libraries and other sector in the economy were neither here nor there in the past fifteen years. In the past decade, whatever has been done in terms of modern technological application or automation has not gone deep enough to make any appreciable impact. For instance, many Nigerian libraries faced various problems in their attempt to computerize their library operations. These problems are not really of the library's making but is the usual problem confronting most of the computer installations all over the country today-shortage of manpower and lack of spare parts. Coupled with this, of course, is the problem of constant computer breakdown and low level of electricity supply. These problems have really slowed down the activities of Nigerian university libraries and other organizations in utilizing the computer-stored information for the services of its clientele.

One is however happy to note that since the past five years, things have been changing for better as far as information technology in library operation in Nigeria is concerned. Until a few years ago, it was generally assumed that computer technology was not viable in Nigerian libraries. However, some university libraries are now either computerizing some of their activities through their respective university's Computer Centres or installing these computers in their own libraries. Private sectors are not left out in this information technological revolution. Nigerian university campuses are now jam-packed with Information Communication technology facilities. It is no longer strange to see lecturers 
and students doing their researches and other academic works using various IT devices like email and Internets. One is happy to note that both the federal government of Nigeria and other international funding agencies are now interested in the general development of ICT in higher education in Nigeria. For example, Federal Ministry of Education has embarked on the establishment of National Virtual (Digital) Library Project. One of the objectives of this is to provide, in an equitable and cost effective manner, enhanced access to national and international library and information resources and for sharing locally-available resources with libraries all over the world using digital technology. A model Virtual (Digital) Library at National Universities Commission (NUC) will be the hub of the university-based libraries. The delivery of the Virtual Library will be through the Internet, CDROM and Wide Area Network (WAN). When this is fully materialized, it will definitely be a boost to the development of ICTs in Nigerian educational system. Some other international funding agencies like Carnegie Corporation of New York are interested in Nigerian ICT developmental programme. Carnegie Corporation also supports the establishment of scientific databases at the University of Ibadan, Nigeria. With similar grants for academic development, the Corporation is presently in collaboration with Obafemi Awolowo University, Ile-Ife, Nigeria and the university library is well positioned to gain from the grant. For instance, through the various grants from these international granting agencies, Information Technology and Communication Unit ( INTECU) is well established on the campus of Obafemi Awolowo University Ile-Ife and it is at present responsibles for the Internet services in the university, in other words, it is a major ICT provider on the campus.

\section{REVOLUTION OR EVOLUTION}

In dealing with the subtitle of this paper, attempt is made to show whether there has been a revolution in the adoption and development of information technology in Nigeria, especially in support of library development. If there has not been any revolution, then we should decide whether there has been as much as an evolutionary trend. A revolution may be regarded as a radical and abrupt change of circumstances or system. Evolution also involves changes but rather an unfolding of events, a gradual develop- ment from a simple or primitive to an advanced system (Ehikhamenor, 1993) Information revolution can be described as fundamental changes in the production and use of information, occurring in the late $20^{\text {th }}$ century. Human societies throughout history have had "information specialists" (from traditional healers to newspapers), and they have had "information technologies" (from cave painting to accountancy) but two interested developments, social and technological, underpin the diagnosis that an information revolution is now occurring. The tremendous advancement in computer technology, software engineering and telecommunications as well as the resultant radical changes and advances in the techniques of data and information processing, storage, retrieval and dissemination, in developed countries within the brief period between the mid-1990s and the late 2000s is, no doubt, a revolution. Information processing has become increasingly visible and important in economic, social, and political life. The informationprocessing aspects of all work can be reshaped through information technology. In the past years many Nigerian university libraries made unsuccessful attempts to computerize their libraries; many are still being hunted by the fear of failure. But in the past 5-10 years many Nigerian libraries are now either computerizing some of their activities through their respective University Computer Centres or installing these computers in their own libraries. As indicated earlier, many university campuses are now jampacked with ICT facilities. It is no longer strange to see lecturers and students doing their researches and other academic works using various electronic devices like e-mail and Internets. This information revolution is not limited to higher institutions alone, both government and private sectors in Nigeria are now making use of advanced IT devices to perform their daily works. One is happy to note that both the Federal Government of Nigeria and other international funding agencies are now interested in the general development of ICT in Nigeria especially in higher education. One can conclude that there is obviously a big contrast in the course of information services in Nigeria especially in the past five years.

\section{CONCLUSION AND RECOMMENDATIONS}

It is possible to assert outright that the means that will give the system of education and training 
its new face in line with the expectations of the new millennium are those that are drawn from the new Information and Communication Technologies. Higher education institutions in Nigeria now face the challenge of globalization and information age for the transformation of the academic system from traditional role of teaching, learning, research and development methodologies to those driven by the information technology, which is the latest revolution changing all aspects of human endeavvour. Infrastructural, institutional as well as human capital capacities must be developed in other to face this challenge. In this regard, as pointed out by Ndiaye (2001) the tool of computer science must be perceived and considered as a 21 st century universal language. With this consideration, its introduction in the educational system and other aspects of national economy must and will be increasingly early and its use will tend to be generalized. This revolution will bring about vast development in the national educational advancement and economic systems. The use of this revolution will give knowledge a universal character by increasing access and ensuring the effectiveness of education throughout the country. But it must be realized that those who will benefit from these IT revolution first are those who will master them first. From this perspective, Nigeria which has started late must sit up by trying to understand the stakes well in order to make up for lagging behind. To do this, one need first, after a strong political will to have equipment that should facilitate the significant and irreversible introduction of these new technologies in the educational system and at all levels while bearing in mind the fact that the small Nigerian child at the kindergarten will be as efficient as the American, the European or the Asian child of the same age when he is placed in the same conditions.

Trainers must also be taught during training programmes to be able to master the use of the technologies but also to enable them to develop especially teaching aids and materials that go with these new technologies. By referring to the UNESCO plan of action for strengthening inter university cooperation and academic mobility; we will begin by recalling that "institutions of higher education play a major role in the creation, transfer and application of knowledge, in the training of cadres, technicians and managers, in the building of cultural identity and in the creation of democratic processes". Developing countries in particular cannot expect to control and apply the most recent discoveries let alone, make important contributions to academic and scientific progress if they do not have institutions of higher education and research that meet the highest standards. It is only by developing their talents and skills, that they will succeed in bridging the gap between them and industrialized countries and be less dependent on a permanent technical assistance. If colleges and universities in Nigeria are to become contemporary and effective organizations, their strategic academic technology agenda should be focused on the production of intelligence rather than on the storage and recall of random and quickly moded information. Universities are complex cultures that create, order and manage information and are constituted as dense information networks held together by ideological and technological strands. The use of IT as a strategic management and cognitive tools is critically important if Nigerian universities wish to be run efficiently, access information through worldwide networks and be globally competitive. These new technologies by giving access to data-bases, libraries, information sources and Web Sites, offer the universities very promising means for the improvement of education and access to information. In other to access these new education means it is necessary to:

- Strengthen the higher education institutions potential in competent human resources and equipment of the new information and communication technologies.

- Promote the establishment of centres of excellence in this networking area.

- Develop the culture and practice of new technologies within the society in general and the university in particular.

- Set up a highly profitable inter-university Internet network to facilitate the exchanges, the video-conferences and the distance education.

It must be realized that most higher educational institutions in Nigeria even those with good Internet connectivity are still at the low level of the integration of ICT into teaching, learning, research, library, information and managerial services. There is the need of professional development in the integration of information technology into education and learning. For the survival and relevance of these higher institutions, ICT should be declared an institutional 
priority with adequate funding and support. The lack of modern equipment in university laboratories and libraries can be compensated, to some extent, by creating networks of training centres and certified consultants by leading ICT companies in Nigeria. Nigerian private companies in the ICT sector should be able to deliver courses through their training centres, which would successfully complement traditional education. The scope of this training will extend beyond the purely academic community and this will address many specific sectors. Several hundred students will be able to take part in these courses offered by the academics and training centres of private ICT companies. From the above analysis, one can conclude that any college or university in Nigeria that does not have full Internet connectivity with reasonable speed and relevant ICT facilities in the next few years will not be in a position to fulfill the purposes for its establishment. This is therefore the time to act; Nigerian universities and Nigeria as a nation have to run very fast to avoid falling very far behind.

\section{REFERENCES}

Capron, H. L. 2000. Computers for an Information Age. New Jersey: Prentice Hall. pp.178.

Conference on Training Information Science Specialists. Oct. 12- 13, 1961 and April 12-13, 1962. Proceedings. Atlanta, Georgia: Institute of techno$\log y$.

Ebeniro, J. O. 2000. "Role of the University in New Technology Acquisition". Committee of ViceChancellors of Nigerian Federal Universities $18^{\text {th }}$ Annual Seminar, PortHarcourt, November $13^{\text {th }}$ $17^{\text {th }}$. Proceedings. pp. 139.

Economic and Social Commission for Asia and the Pacific (ESCAP). 2000. "Are ICT Policies Addressing Gender Equality?" http//www unescap-org/wid/04 widresources/11 wideactivites/0 1 c cteg m/ backgroundpaper. Pdf.

Ehikhamenor, F. A. 1993. "Information Technology and Scientific and Technological Information in Nigeriua: Revolution or Evolution? African Journal of Library, Archives and Information Science, 3 (2): 119 .

Encarta Encyclopedia. 2002. "Information Science". Microsoft Encyclopedia.

Hargittai, E. 1999. "Weaving the Western Web: Explaining Differences in Internet Connectivity among OECD Countries". Telecommunications Policy, 23: 701-718.

Ikurionan, Ebhorhor and Eribenna, Ifeoma 1991. "NITEL's Digital System now ready". Daily Times, Thursday October, pp.2.

Kiiski, S. and M. Pohjola. 2001. "Cross-country diffusion of the Internet" available at http//www.wider unu. edu/publications/dps/Dp2001-11.pdf.

Marcelle, G. 2000. "Gender, Justice and ICTs". http:// www.un.org/womenwatch daw/csw/marcello.htm.

Ndiaye, Ahmadou Lamine. 2001. "African Universities and the Challenge of Knowledge Creation and Application in the New Century". Association of African Universities $10^{\text {th }}$ General Conference. Proceedings. Nairobi, Kenya. February 5-9. pp.80.

Nilles, J. M. 1987. "Future Impacts of Information Technology, Science and the Future". Year Book Encyclopedia Britannica Inc. pp. 513-520.

Ofulue, O. N. 1980. "Telecommunications Services in Nigeria in the Seventies: An Overview". Paper presented at Nigerian Society of Engineers National Engineering Conference, Enugu, Nigeria, 4-6 December.Proceedings.

Osundina, O. 1973. "The Relationship between Information Science and Librarianship: A Viewpoint". Nigerian Libraries, 9 (1 \& 2): 47.

Rodriguez, F. and E. Wilson. 2000. "Are Poor Countries Losing the Information Revolution?" mfoDev Working Paper. Washington D.C.: World Bank.

Tristnikov, V. N. 1970. "Information" Great Soviet Encyclopedia. New York: Macmillan, Inc. (10): 274

Ubogu, F. N. and D. K. Gupta. 1987. "Problems and Possibilities of Computer Application in Library Automation and Information Work in Nigeria", (pp.549-555) in J. D. Lehmann and H. StrohlGoebel. (eds.), The Application of Micro-Computers in Information, Documentation and Libraries. North-Holland: Elsevier Science Publishers.

Ukoh, K. A. 1984. "Application of Modern Technology in the Library. Nigerian Library and Information Science Review, 2(1\&2): 3

Unchidiuno, P. C. 1986. "Dedicated Satellite Communications System and NITEL Services". Paper presented at the International Seminar on Satellite Communication Systems for Nigeria, $21^{\mathrm{st}}$ $23^{\text {rd }}$ July. 